\title{
GENERAL INNOVATION FRAMEWORK AND THE INNOVATION EXPECTATIONS OF RURAL ACTORS
}

\section{Cosmin Sălășan, Sebastian Moisa, IoAna M. Bălan, Carmen Dumitrescu}

\author{
Banat's University of Agricultural Sciences and Veterinary Medicine "King Michael Ist of \\ Romania" from Timișoara, \\ Faculty of Agricultural Management \\ Calea Aradului 119, RO-300645 Timișoara, Romania \\ cosminsalasan@gmail.com
}

\begin{abstract}
The analysis of the general and the further-on more specific innovation framework targeting the rural area and the rural economy begins by screening the general statistic data and continues by an in-depth investigation of the options and opinions of relevant rural actors at the scale of a well-defined rural micro region, in our case a Local Action Group territory. The choice of the local scale should build on the previously acquired experience in project-based developments and the general high favourability for rural development for the specific region. The moment of the investigation is also an observation choice linked to the specific inputs of information and advice during the sessions of information and animation requested during the formulation stage of the future Local Development Strategies. The moment is highly relevant since it places the overall accessible support framework in the development perspectives and even more, in the formulated development intentions on medium term for an entire territory. The collection of facts and observations about the current state and the developments in the field of Research, Development and Innovation are compared to the real expectations and the development intentions of the local rural actors. The measure of the gap between the nationally programmed instruments and the real developments in agriculture and rural economy indicates the fitness level of the top-down programming approach.
\end{abstract}

Keywords: innovation framework, rural development, rural actors' expectations

\section{INTRODUCTION}

The need for strengthening the innovations' impact in rural development originates in early community initiatives and becomes a supported development opportunity for the first time in the EU's National Rural Development Programmes (NRDPs) 2007-2013. Although not introduced from the very beginning (EIP-AGRI, 2012) other than a transversal priority it was later incorporated as part of the Rural Development Programmes (RDPs) and supplemented with funds for dedicated interventions (Romanian NRDP 2007-2013, 2012). The current layout of the programmes, namely the EU's 2014-2020 RDPs and the Romanian NRDP (Romanian NRDP 2014-2020, 2016) further include the European Innovation Partnership for Agricultural productivity and Sustainability as a core component for the innovation support designated to smart rural areas. The overall approach of the innovation at national level is rather focused on spinning business and mainstream sectors with no particular emphasis on rural or agriculture other than the dedicated interventions pointing to the bioeconomy. The current Romanian RDP has directed the support for innovation and transfer of innovative products and process mainly towards a sub-measure - sM 16 Support for cooperation (Romanian NRDP 2014-2020, 2016) which is still inaccessible due to a long delayed official launch. On the side of the rural actors and farmers' communities the demand is not only present but also relatively well formulated as highlighted by the findings of the present paper. 


\section{MATERIAL AND METHOD}

The localised data is collected and analysed by interview survey as primary research method. Bridging with the national relevance and findings was performed by secondary research based on data from official statistics sources selected and compiled by secondary analysis for the relevant variables (NIS, 2017). No qualitative methods were employed in order to induce a maximum of objectivity strictly linked to findings and observations.

\section{RESULTS}

Within the precise target of fixing the current expectations and the development intentions linked to the transfer of innovation at the most local scale a screening of the national framework is required. In this respect, we will pinpoint the recent evolutions, where applicable and relevant capturing almost two decades of changes, in line with a selected number of indicators as followed by the methodology of the Community Innovation Survey (CIS, 2016). The heterogeneous series will capture the evolution of the number of units with research and innovation activities, the number of innovative companies with focus on the West Region where the surveyed LAG is situated, the turnover evolution of the innovative companies in Romania where the focus goes for the SMEs, the typology of the innovators and its evolution since 2002 and the selected typologies of RDI projects for agriculture and agricultural sciences.

The evolution of the total number of units developing research and innovation activities over a period of eighteen years is presented in the Table 1 and illustrated graphically in Figure 1 bellow.

Table 1. Units with Research and Development activities by sectors, 1993-2010 (no.)

\begin{tabular}{|c|c|c|c|c|c|c|}
\hline & Sectors & Total & $\begin{array}{c}\text { Business } \\
\text { sector }\end{array}$ & $\begin{array}{c}\begin{array}{c}\text { Governmental } \\
\text { sector }\end{array} \\
\end{array}$ & $\begin{array}{c}\text { Higher } \\
\text { Education }\end{array}$ & NGO \\
\hline \multirow[t]{18}{*}{ Years } & 1993 & 617 & 460 & 120 & 37 & - \\
\hline & 1994 & 591 & 452 & 105 & 34 & - \\
\hline & 1995 & 615 & 454 & 120 & 41 & - \\
\hline & 1996 & 616 & 455 & 122 & 39 & - \\
\hline & 1997 & 645 & 496 & 109 & 40 & - \\
\hline & 1998 & 643 & 493 & 114 & 36 & - \\
\hline & 1999 & 626 & 473 & 109 & 44 & - \\
\hline & 2000 & 601 & 439 & 110 & 52 & - \\
\hline & 2001 & 609 & 424 & 116 & 69 & - \\
\hline & 2002 & 607 & 409 & 114 & 84 & - \\
\hline & 2003 & 719 & 488 & 120 & 86 & 25 \\
\hline & 2004 & 753 & 523 & 120 & 79 & 31 \\
\hline & 2005 & 806 & 563 & 124 & 85 & 34 \\
\hline & 2006 & 884 & 559 & 177 & 108 & 40 \\
\hline & 2007 & 787 & 506 & 165 & 86 & 30 \\
\hline & 2008 & 775 & 491 & 164 & 103 & 17 \\
\hline & 2009 & 667 & 426 & 134 & 97 & 10 \\
\hline & 2010 & 660 & 410 & 129 & 102 & 19 \\
\hline
\end{tabular}

Source: National Institute of Statistics, TEMPO Online data series, interrogated 04.2017

As general observation it is notable, and to a certain extent, unexpected that the major changes in the peak period before the crisis were induced by the shifts in number in the public sector. The end of the Romania's pre-accession to EU led to an unnatural growth from 124 to 177 units in the governmental sector in a single year that washed away during 
the next half decade. Other than this evolution the general trend is set by the business sector as observed in Figure 1. Also, worth mentioning that the higher education continued the growth recorded at the beginning of the millennia and managed to sustain the growth even during the crisis years (2008-2010).
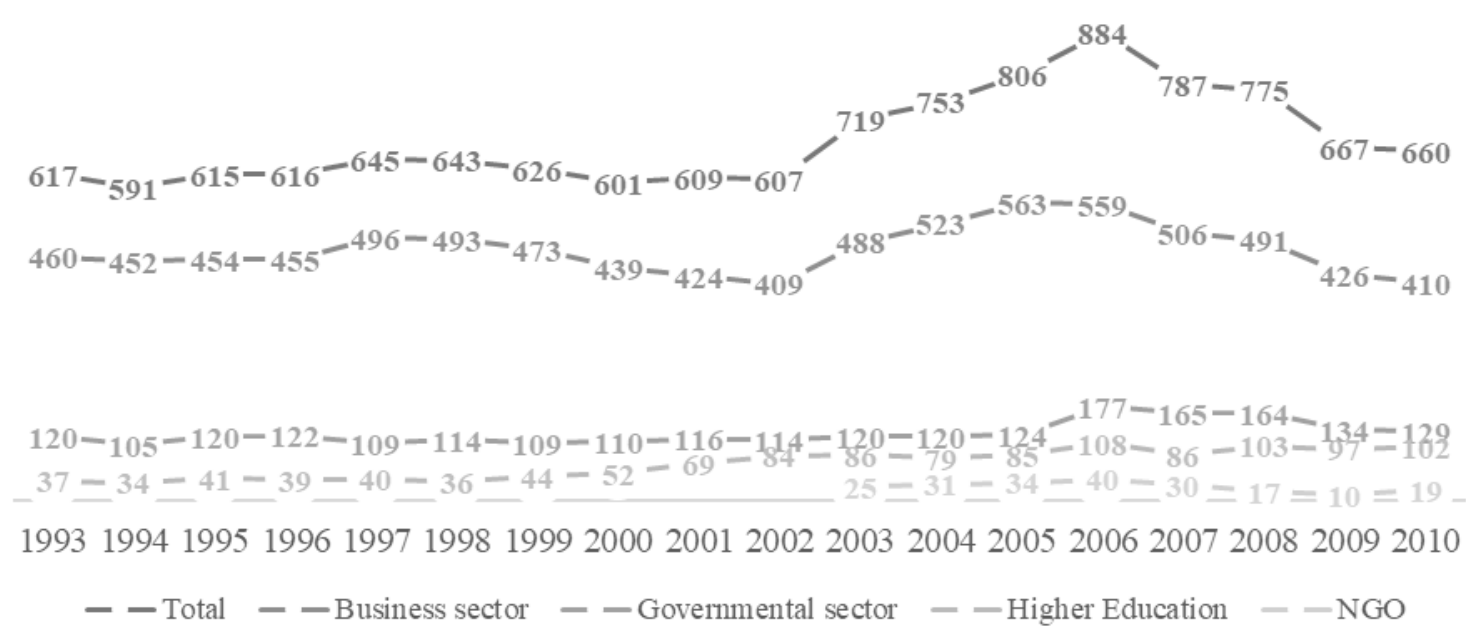

Figure 1. Entities with RDI activities in Romania, 1993-2010 (number)

Source: Based on data from National Institute of Statistics, TEMPO Online data series, interrogated 04.2017

Contrary to the general belief and the common knowledge in the region the number of innovative companies is rather lagging behind other regions in the country. If the relative and absolute figures regarding the IT\&C companies and other companies involved in high tech and automotive parts active in the West Region is considerable larger than in most other regions of the country in 2014 only 5\% of the innovative companies in Romania were placed and still active here. As presented in Table 2, this share is a decrease with more than 100 companies over the past decade while the number of non-innovative companies increased by more than $10 \%$ to the reference initial year of the period.

Table 2. Innovative companies at national and regional level, 2002-2014 (no., \%)

\begin{tabular}{|c|c|c|c|c|c|c|c|c|}
\hline \multicolumn{2}{|c|}{} & \multicolumn{7}{c|}{ Years } \\
\cline { 3 - 9 } & TOTAL & $\mathbf{2 0 0 2}$ & $\mathbf{2 0 0 4}$ & $\mathbf{2 0 0 6}$ & $\mathbf{2 0 0 8}$ & $\mathbf{2 0 1 0}$ & $\mathbf{2 0 1 2}$ & $\mathbf{2 0 1 4}$ \\
\hline \multirow{2}{*}{ Total } & WEST Region (\%) & $11 \%$ & $10 \%$ & $10 \%$ & $10 \%$ & $10 \%$ & $9 \%$ & $10 \%$ \\
\hline & WEST Region (no.) & 2481 & 2723 & 2959 & 3002 & 2532 & 2672 & 2724 \\
\hline $\begin{array}{l}\text { Innovative } \\
\text { companies }\end{array}$ & TOTAL & 3983 & 5171 & 6013 & 9986 & 8116 & 5968 & 3645 \\
\hline & WEST Region (\%) & $7 \%$ & $7 \%$ & $5 \%$ & $6 \%$ & $6 \%$ & $6 \%$ & $5 \%$ \\
\cline { 2 - 9 } & WEST Region (no.) & 291 & 354 & 329 & 616 & 469 & 384 & 175 \\
\hline $\begin{array}{c}\text { Non- } \\
\text { innovative } \\
\text { companies }\end{array}$ & TOTAL & 19421 & 20853 & 22475 & 19993 & 18214 & 22898 & 24735 \\
\hline & WEST Region (\%) & $11 \%$ & $11 \%$ & $12 \%$ & $12 \%$ & $11 \%$ & $10 \%$ & $10 \%$ \\
\cline { 2 - 10 } & WEST Region (no.) & 2190 & 2369 & 2630 & 2386 & 2063 & 2288 & 2549 \\
\hline
\end{tabular}

Source: National Institute of Statistics, TEMPO Online data series, interrogated 04.2017

The turnover of the companies over the same decade containing both the pre-accession (2002-2007) and the integration period of Romania to EU or the first programming period 
as EU member state (2007-2014) allow the observation of uneven evolutions and most likely a high dependency to investments for the innovative companies. As presented in Table 3 below, the general turnover has multiplied over four times (4.3 times) during the observed period if compared the beginning and the end of the period. For the grand total including all kind of companies the growth was almost linear while for the innovative companies the evolution was rather Gaussian stabilising to a factor three growth at the end of the period. However, if in 2002 the contribution of the innovative companies was representing over $40 \%(41.53 \%)$ in 2014 it represents little over 30\% (31.29\%). Although the evolution of the total and the innovative companies, particularly the SMEs, is slightly parallel it is interesting to observe the relative stability as share from total of the small and medium enterprises as presented in the Figure 2.

Table 3. Turnover of innovative enterprises in Romania, 2002-2014 (Thou. ROL)

\begin{tabular}{|c|c|c|c|c|c|c|c|c|}
\hline & $\mathbf{2 0 0 2}$ & $\mathbf{2 0 0 4}$ & $\mathbf{2 0 0 6}$ & $\mathbf{2 0 0 8}$ & $\mathbf{2 0 1 0}$ & $\mathbf{2 0 1 2}$ & $\mathbf{2 0 1 4}$ \\
\hline \multicolumn{8}{|c|}{ Total } \\
\hline Total & 185.533 .699 & 298.028 .917 & 457.951 .764 & 648.366 .728 & 580.659 .532 & 667.323 .194 & 800.965 .586 \\
\hline Small & 38.032 .185 & 65.965 .454 & 85.589 .822 & 121.410 .952 & 108.080 .006 & 143.290 .933 & 147.439 .300 \\
\hline Medium & 39.145 .696 & 67.217 .615 & 94.767 .755 & 146.019 .979 & 148.342 .548 & 161.056 .062 & 174.219 .298 \\
\hline Large & 108.355 .818 & 164.845 .848 & 277.594 .187 & 380.935 .797 & 324.236 .978 & 362.976 .199 & 479.306 .988 \\
\hline \multicolumn{8}{|c|}{ Innovative enterprises } \\
\hline Total & 77.051 .452 & 135.533 .473 & 219.737 .312 & 391.459 .502 & 339.489 .595 & 267.691 .818 & 250.620 .882 \\
\hline Small & 5.482 .718 & 13.245 .118 & 15.522 .111 & 41.972 .042 & 35.314 .050 & 27.921 .021 & 19.799 .237 \\
\hline Medium & 10.054 .396 & 22.319 .117 & 30.117 .481 & 75.224 .154 & 65.432 .493 & 51.760 .922 & 37.884 .374 \\
\hline Large & 61.514 .338 & 99.969 .238 & 174.097 .720 & 274.263 .306 & 238.743 .052 & 188.009 .875 & 192.937 .271 \\
\hline
\end{tabular}

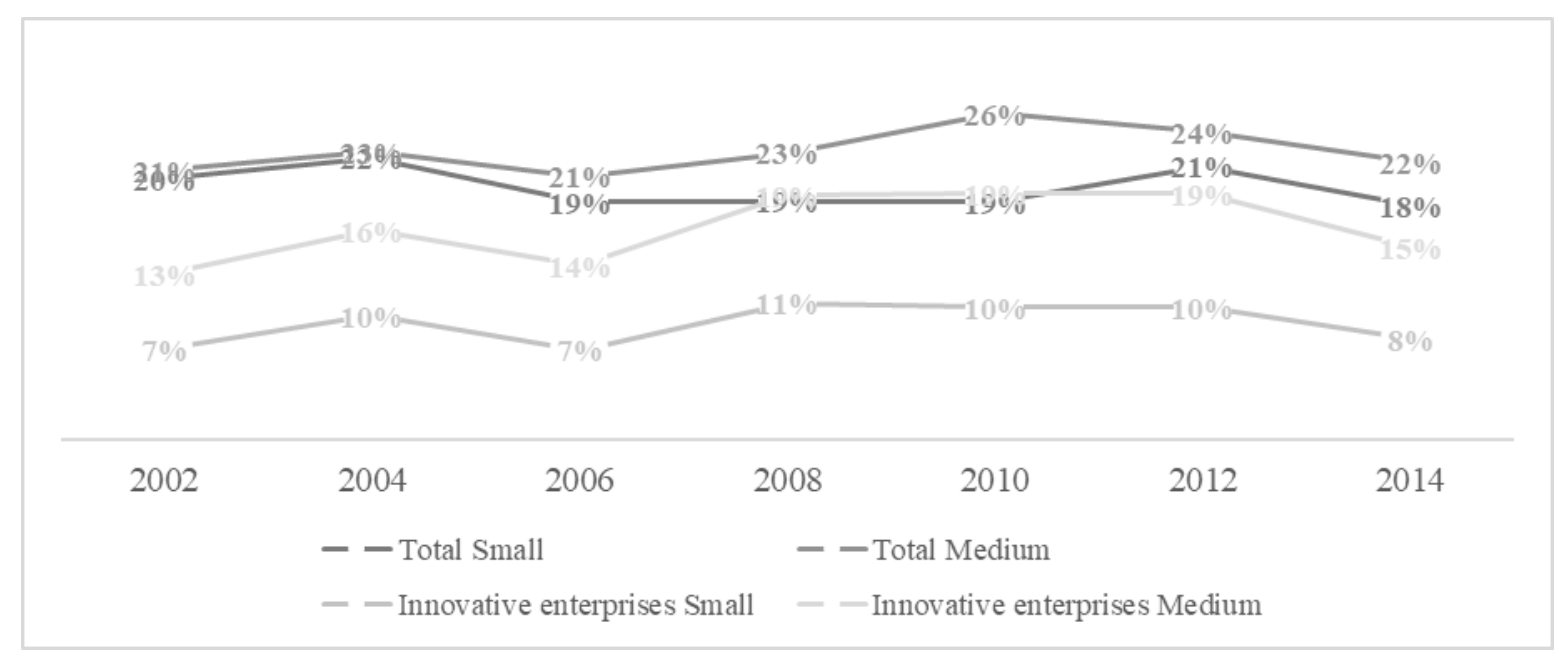

Figure 2. Turnover of innovative SMEs in Romania, 2002-2014 (\%)

Source: Based on data from National Institute of Statistics, TEMPO Online data series, interrogated 04.2017

These evolutions observed above can be approached from the inside if we address the typology of the innovators and the evolution of these categories over the same time period (Table 4). The most dramatic evolutions regard the innovators with unfinished or abandoned activities where the figures increased fifteen times representing $8 \%$ from the total number of innovative enterprises in 2014. Also, the number of successful innovators has decreased by more than half while the number of non-innovative enterprises has increased by one third over the last four years of the observed period. 
Table 4. Typology and evolution of innovators, 2002-2014 (no.)

\begin{tabular}{|c|c|c|c|c|c|c|c|}
\hline \multirow{2}{*}{ Types of innovators } & \multicolumn{7}{|c|}{ Years } \\
\hline & 2002 & 2004 & 2006 & 2008 & 2010 & 2012 & 2014 \\
\hline Total & 23404 & 26024 & 28488 & 29979 & 26330 & 28866 & 28380 \\
\hline Innovative enterprises & 3983 & 5171 & 6013 & 9986 & 8116 & 5968 & 3645 \\
\hline $\begin{array}{c}\text { Enterprises with only product and/or process } \\
\text { innovation }\end{array}$ & $:$ & : & $:$ & 1951 & 1137 & 541 & 988 \\
\hline $\begin{array}{c}\text { Enterprises with only organisation and/or } \\
\text { marketing innovation }\end{array}$ & : & : & : & 4079 & 4353 & 4162 & 1805 \\
\hline $\begin{array}{l}\text { Enterprises with product and/or process } \\
\text { innovation and organisation and/or marketing } \\
\text { innovation }\end{array}$ & : & : & : & 3956 & 2626 & 1265 & 852 \\
\hline $\begin{array}{l}\text { Successful innovators } \\
\end{array}$ & 3963 & 5136 & 5970 & 5748 & 3631 & 1691 & 1529 \\
\hline Product only innovators & 582 & 472 & 525 & 710 & 635 & 351 & 313 \\
\hline Process only innovators & 413 & 1203 & 1169 & 1965 & 955 & 706 & 511 \\
\hline Product and process innovators & 2968 & 3461 & 4276 & 3073 & 2041 & 634 & 705 \\
\hline $\begin{array}{c}\text { Innovators with unfinished or abandoned } \\
\text { activities }\end{array}$ & 20 & 35 & 43 & 159 & 132 & 115 & 311 \\
\hline Non-innovative enterprises & 19421 & 20853 & 22475 & 19993 & 18214 & 22898 & 24735 \\
\hline
\end{tabular}

Source: National Institute of Statistics, TEMPO Online data series, interrogated 04.2017

Observing the evolution of RDI projects within the frame of agriculture and general promotion of agricultural sciences (Table 5) the past five years 2011-2015 have a very heterogeneous evolution. The number of programmes for agriculture according to the NABS 2007 is relatively large considering the entire range of covered sectors reaching over $10 \%$ in 2015 . However, the evolution over this short and recent period of time has oscillations far too large to be comprehensible. The only pertinent observation with regard to this evolution indicates lack of consistency and respectively an absence of a strategic intervention for both General University Funds or other sources.

Table 5. Typology of RDI projects, 2011-2015 (no.)

\begin{tabular}{|c|c|c|c|c|c|}
\hline Type of RD programmes (NABS 2007) & \multicolumn{5}{|c|}{ Years } \\
\hline Total, of which NABS programmes: & $\mathbf{2 0 1 1}$ & $\mathbf{2 0 1 2}$ & $\mathbf{2 0 1 3}$ & $\mathbf{2 0 1 4}$ & $\mathbf{2 0 1 5}$ \\
\hline Agriculture & 9518 & 8394 & 7421 & 8143 & 7872 \\
\hline $\begin{array}{c}\text { General promotion of knowledge: RD financed } \\
\text { from General University Funds (GUF), for: }\end{array}$ & 2161 & 2073 & 1033 & 1066 & 1663 \\
\hline Agricultural sciences & 93 & 30 & 32 & 36 & 94 \\
\hline $\begin{array}{c}\text { General promotion of knowledge: RD financed } \\
\text { from other sources than GUF, for: }\end{array}$ & 3502 & 2898 & 2496 & 3460 & 2763 \\
\hline Agricultural sciences & 53 & 21 & 48 & 56 & 31 \\
\hline
\end{tabular}

Source: National Institute of Statistics, TEMPO Online data series, interrogated 04.2017

The micro-regional scale of the LAG allows its actors to be closely connected to the current and future development opportunities and well placed in the public policy support mainstream. From the total of 189 participants to the animation and information sessions almost one third have responded to the question related to the innovative projects expected in their future LAG. This is figure does not surprise by its low level considering the spectrum of the participants where representatives of local authorities count for $45 \%$ of the future members and other NGO representatives, farmers and rural entrepreneurs have a more ardent set of priorities. Of high relevance is the observation that three out of the first five most ranked options representing almost $1 / 2(47.46 \%)$ of the total number of expressed options are non-agricultural while $1 / 3(33.90 \%)$ are directly linked to the agriculture (Table 6). 
Review on Agriculture and Rural Development 2017 vol. 6 (1-2) ISSN 2063-4803

Table 6. Innovative projects' intentions/expectations in LAG (no., \%)

\begin{tabular}{|c|c|c|}
\hline Options & Number & Share of total respondents \\
\hline Non-agricultural activities, services, rural business & 12 & $\mathbf{2 0 . 3 4 \%}$ \\
\hline Public physical infrastructure & 10 & $\mathbf{1 6 . 9 5 \%}$ \\
\hline Culture and sport activities/events & 6 & $\mathbf{1 0 . 1 7 \%}$ \\
\hline Information, dissemination and communication & 5 & $\mathbf{8 . 4 7 \%}$ \\
\hline Agricultural infrastructure & 4 & $\mathbf{6 . 7 8 \%}$ \\
\hline Processing (of agricultural outputs) & 4 & $\mathbf{6 . 7 8 \%}$ \\
\hline Alternative energy & 4 & $\mathbf{6 . 7 8 \%}$ \\
\hline Modernising the agriculture & 3 & $5.08 \%$ \\
\hline Environment & 3 & $5.08 \%$ \\
\hline Culture and sport infrastructure & 2 & $3.39 \%$ \\
\hline Conditioning and storage & 2 & $3.39 \%$ \\
\hline Marketing, markets, association and producer groups & 2 & $3.39 \%$ \\
\hline Social activities/events & 1 & $1.69 \%$ \\
\hline Social infrastructure & 1 & $1.69 \%$ \\
\hline
\end{tabular}

Source: Processed primary interview survey data 02.2016

The high level of interest for non-agricultural innovation, moreover for innovative approaches linked to the social aspects, services, public infrastructure, culture and sport coming upfront environment or alternative energy indicates a precise concern for the increase of the quality of life in rural area unprecedented in earlier priority sets and linked to the potential input and impact of the innovation in rural life.

\section{CONCLUSIONS}

The findings highlight the realism of the local actors' expectations closely linked with the vocation for development of the territory, the priorities and the strategic goals at a microregion scale. The innovation framework particularly for agriculture and rural area could further take into consideration the possibility to operate with a finer tuning in terms of territorial and sectoral iterations. The current replication of national and community assumed priorities organised in unique sets and presents for innovation and its transfer as product, process or both appears to be less appealing for the rural local actors. Shifting the target from companies or business entities towards actors and their forms of representation including networks or early unstructured clusters could represent a change with a considerably higher impact in the Romanian rural area.

\section{REFERENCES}

EIP-AGRI, 2012, European Innovation Partnership, https://ec.europa.eu/eip/agriculture/en, visited 04.2017

EUROSTAT, Community Innovation Survey (CIS), 2016, http://ec.europa.eu/eurostat/web/microdata/community-innovation-survey

NIS, 2017, Romanian National Institute of Statistics, TEMPO Online data series, interrogated 04.2017

NRDP 2007-2013, 2012, National Rural Development Programme of Romania 2007-2013, http://www.madr.ro/pndr-2007-2013/programul-national-pentru-dezvoltare-rurala-2007-

2013.html, visited 04.2017

NRDP 2014-2020, 2016, National Rural Development Programme of Romania 2014-2020, http://www.madr.ro/pndr-2014-2020/implementare-pndr-2014-2020/documente-

aprobate.html, visited 04.2017 